\section{POS0911 SIMILAR CLINICAL RESPONSES ACHIEVED WITH LOWER VERSUS STANDARD DOSES OF INFLIXIMAB BIOSIMILAR CT-P13 IN PATIENTS WITH ANKYLOSING SPONDYLITIS: REAL-WORLD RESULTS FROM THE RAAS STUDY}

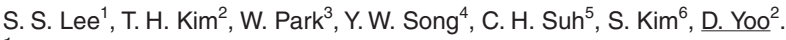
${ }^{1}$ Chonnam National University Medical School \& Hospital, Department of Rheumatology, Gwangju, Korea, Rep. of (South Korea); ${ }^{2}$ Hanyang University Hospital for Rheumatic Diseases, Department of Rheumatology, Seoul, Korea, Rep. of (South Korea); ${ }^{3}$ Inha University, School of Medicine, Incheon, Korea, Rep. of (South Korea); ${ }^{4}$ Seoul National University College of Medicine, Seoul National University Hospital, Department of Internal Medicine, Division of Rheumatology, Seoul, Korea, Rep. of (South Korea); ${ }^{5}$ Ajou University School of Medicine, Department of Rheumatology, Suwon, Korea, Rep. of (South Korea); ${ }^{6}$ Celltrion Healthcare Co., Ltd., Medical Affairs Department, Incheon, Korea, Rep. of (South Korea)

Background: CT-P13, an infliximab biosimilar, is effective for treating ankylosing spondylitis (AS) at a dose of $5 \mathrm{mg} / \mathrm{kg}$ infused once every 6-8 weeks. Evidence suggests that patients with AS may benefit from a lower dose, and individualised dose/interval adjustments should be based on treatment response.

Objectives: To analyse real-world treatment patterns (doses and infusion intervals) and outcomes for CT-P13-treated patients with AS over 5 years.

Methods: The RAAS study collected medical record data for adults with AS treated with CT-P13 at five referral hospitals in the Republic of Korea (20122017). Patients were infliximab naïve at CT-P13 initiation ('naïve') or had switched to CT-P13 from reference infliximab ('switched'). Patients were analysed by baseline dose (BD) $(<4 \mathrm{mg} / \mathrm{kg} ; \geq 4-<5 \mathrm{mg} / \mathrm{kg} ; \geq 5 \mathrm{mg} / \mathrm{kg}$ ), defined as the third (naïve) or first (switched) infusion dose. Baseline infusion intervals were the average of the three infusion intervals after BD. Over time, patients with both constant dose and infusion interval were compared with those with changes in dose and/or infusion interval. Data were analysed by Kruskal-Wallis test, chi-squared test and oneway analysis of variance, and drug survival by log-rank test.

Results: Overall, 337 patients (219 naïve; 118 switched) were identified. Of those with BD data, 71,117 and 82 patients had BDs of $<4 \mathrm{mg} / \mathrm{kg}, \geq 4-<5 \mathrm{mg} / \mathrm{kg}$ and $\geq 5 \mathrm{mg} / \mathrm{kg}$, respectively. Most patients were male $(74.8 \%)$. Patients with higher BDs tended to have higher Bath Ankylosing Spondylitis Disease Activity Index (BASDAl) scores; switched patients had lower scores than naïve patients. Of 186 evaluable patients (118 naïve; 68 switched), 85 (46 naïve; 39 switched) did not have dose and/or interval changes ('combined constant' group). More naïve $(n=72 ; 61.0 \%)$ versus switched $(n=29 ; 42.6 \%)$ patients had dose and/or interval changes ('combined changed' group). Considering dose and interval separately, 18/235 evaluable patients (152 naïve; 83 switched) had dose changes (12 increased; 6 decreased) and 110/224 evaluable patients (140 naïve; 84 switched) had interval changes (79 increased; 31 decreased). Cumulative annual doses were similar between naïve and switched patients; switched patients had longer infusion intervals than naïve patients (Figure 1). There were no significant differences in drug survival between BD groups overall or for naïve and switched patients. BASDAI scores over time showed that disease activity was well controlled (Table 1). Patients in the combined changed versus combined constant group had greater improvements in BASDAl score.

\section{Table 1. BASDAI scores}

\begin{tabular}{|c|c|c|c|c|c|c|c|}
\hline Group & & Statistic & wo & w54 & W102 & W156 & W210 \\
\hline \multirow{12}{*}{$\begin{array}{l}\text { Combined } \\
\text { constant }\end{array}$} & \multirow{4}{*}{ Total (N=85) } & $\mathrm{n}$ & 72 & 73 & 57 & 42 & 31 \\
\hline & & Mean & 5.50 & 2.50 & 2.35 & 2.42 & 2.36 \\
\hline & & (SD) & (3.12) & (1.71) & (1.66) & (1.66) & (1.68) \\
\hline & & Median & 6.32 & 2.60 & 2.40 & 2.55 & 2.60 \\
\hline & \multirow[t]{4}{*}{ Naïve $(n=46)$} & $\mathrm{n}$ & 39 & 39 & 26 & 18 & 12 \\
\hline & & Mean & 7.86 & 2.49 & 2.41 & 2.34 & 1.94 \\
\hline & & (SD) & $(1.45)$ & $(1.82)$ & $(1.75)$ & $(1.70)$ & (1.58) \\
\hline & & Median & 7.80 & 2.20 & 1.75 & 1.90 & 1.44 \\
\hline & \multirow{4}{*}{$\begin{array}{r}\text { Switched } \\
(n=39)\end{array}$} & $\mathrm{n}$ & 33 & 34 & 31 & 24 & 19 \\
\hline & & Mean & 2.71 & 2.50 & 2.31 & 2.48 & 2.63 \\
\hline & & (SD) & (2.07) & $(1.60)$ & $(1.60)$ & $(1.67)$ & (1.73) \\
\hline & & Median & 2.58 & 2.75 & 2.50 & 2.80 & 2.70 \\
\hline \multirow{12}{*}{$\begin{array}{l}\text { Combined } \\
\text { changed }\end{array}$} & \multirow{4}{*}{ Total $(\mathrm{N}=101)$} & $\mathrm{n}$ & 87 & 85 & 76 & 53 & 35 \\
\hline & & Mean & 5.68 & 1.81 & 1.58 & 1.49 & 1.40 \\
\hline & & (SD) & (2.89) & (1.45) & (1.27) & (1.34) & (1.24) \\
\hline & & Median & 6.70 & 1.32 & 1.19 & 1.20 & 1.00 \\
\hline & \multirow[t]{4}{*}{ Naïve $(n=72)$} & $\mathrm{n}$ & 63 & 60 & 54 & 34 & 18 \\
\hline & & Mean & 7.18 & 2.01 & 1.65 & 1.54 & 1.52 \\
\hline & & (SD) & (1.37) & $(1.44)$ & (1.22) & $(1.26)$ & $(0.97)$ \\
\hline & & Median & 7.30 & 1.83 & 1.35 & 1.31 & 1.35 \\
\hline & \multirow{4}{*}{$\begin{array}{r}\text { Switched } \\
\qquad(n=29)\end{array}$} & $\mathrm{n}$ & 24 & 25 & 22 & 19 & 17 \\
\hline & & Mean & 1.74 & 1.33 & 1.42 & $1.39(1.50)$ & 1.28 \\
\hline & & (SD) & (1.94) & (1.36) & (1.41) & & (1.50) \\
\hline & & Median & 0.92 & 0.80 & 0.85 & 0.70 & 0.58 \\
\hline
\end{tabular}

SD, standard deviation; W, Week
Figure. Mean cumulative annual dose and mean infusion interval by treatment group

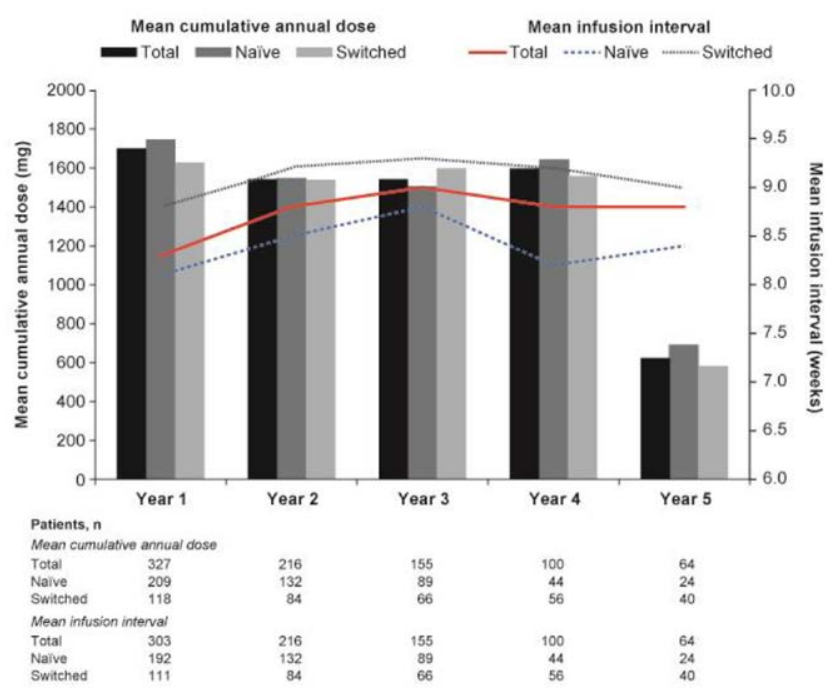

Conclusion: These real-world data demonstrate that adjusting dose and infusion interval can improve clinical outcomes for CT-P13-treated patients with AS Drug survival and BASDAI results show that patients with lower baseline BASDAI receiving low CT-P13 doses can achieve the same outcomes as those dosed with $\geq 5 \mathrm{mg} / \mathrm{kg}$. Findings support the lack of impact of switching from reference infliximab to CT-P13 on efficacy, underlining conclusions previously drawn for efficacy and safety. ${ }^{1}$

REFERENCES:

[1] Kim T-H, et al. Clin Drug Investig 2020;40:541-53.

Acknowledgements: Funding: This study was supported by Celltrion Healthcare Co., Ltd. (Incheon, Republic of Korea). Medical writing support was provided by Beatrice Tyrrell, DPhil (Aspire Scientific, Bollington, UK), and funded by Celltrion Healthcare Co., Ltd. (Incheon, Republic of Korea).

Disclosure of Interests: Shin-Seok Lee: None declared, Tae-Hwan Kim: None declared, Won Park Consultant of: Celltrion, Inc., Yeong Wook Song: None declared, Chang-Hee Suh Speakers bureau: AbbVie Inc., Astellas Pharma Inc., Samsung Bioepis Co., Ltd, Consultant of: Celltrion Healthcare Co., Ltd., Eli Lilly and Company, GlaxoSmithKline plc, Janssen Pharmaceuticals, Yungjin Pharmaceutical, Co., Ltd, SooKyoung Kim Shareholder of: Celltrion Healthcare Co., Ltd. Employee of: Celltrion Healthcare Co., Ltd., DaeHyun Yoo Speakers bureau: Celltrion, Consultant of: Celltrion, Grant/research support from: Celltrion DOI: 10.1136/annrheumdis-2021-eular.1055

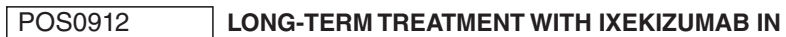 PATIENTS WITH AXIAL SPONDYLOARTHRITIS: TWO- YEAR RESULTS FROM COAST-Y}

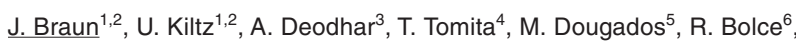
D. Sandoval ${ }^{6}$, D. Adams ${ }^{6}$, C. Y. Lin ${ }^{6}$, J. A. Walsh ${ }^{7} .{ }^{1}$ Rheumazentrum Ruhrgebiet, Rheumatology, Herne, Germany; ${ }^{2}$ Ruhr-Universität Bochum, Rheumatology, Herne, Germany; ${ }^{3}$ Oregon Health \& Science University, Rheumatology, Portland, United States of America; ${ }^{4}$ Osaka University Graduate School of Medicine, Rheumatology, Osaka, Japan; ${ }^{5}$ Hôpital Cochin, Rheumatology, Paris, France; ${ }^{6}$ Eli Lilly and Company, Biomedicines, Indianapolis, United States of America; ${ }^{7}$ University of Utah, Rheumatology, Salt Lake City, United States of America

Background: The efficacy and safety of the interleukin-17 inhibitor ixekizumab (IXE) for the treatment of radiographic ( $\mathrm{r}$-) and non-radiographic (nr-) axial spondyloarthritis (axSpA) has been shown for up to 52 weeks. ${ }^{1-2}$

Objectives: To study the efficacy and safety of ixekizumab in the treatment of patients with $r$ - and nr-axSpA for up to 116 weeks.

Methods: COAST-Y (NCT03129100) is the 2-year extension of the COAST-V, $-W$, and $-X$ trials. Patients continued with the dose received at the end of the originating trial at Week 52, either with $80 \mathrm{mg}$ IXE every 4 weeks (Q4W) or every 2 weeks (Q2W). Patients who had been assigned to adalimumab or placebo were re-randomized to IXE Q4W or Q2W at Week 16 in COAST-V and -W. Patients who had received placebo for 52 weeks in COAST-X were switched to IXE Q4W in COAST-Y. Patients who switched from placebo or adalimumab treatment to IXE (COAST-V, -W, or -X) or from IXE Q4W to open-label IXE Q2W (COAST-X) during the originating studies were analyzed separately from patients continuously treated with IXE. Standardized efficacy measures were used (Table 1). Missing data were handled by non-responder imputation for categorical data 